\title{
Determination of fluoride in spices using microwave induced oxygen combustion
}

\author{
Emanuel Šucman, Jiř́i Bednář \\ University of Veterinary and Pharmaceutical Sciences Brno, Faculty of Veterinary Hygiene and Ecology, \\ Institute of Biochemistry, Chemistry and Biophysics, Brno, Czech Republic
}

Received December 9, 2011

Accepted May 16, 2012

\begin{abstract}
Fluorine is essential in human and/or animal nutrition; therefore, so it is important to know its concentration in a diet. One of the possible sources of fluorine for humans is spice, containing various amounts of this trace element. This work describes the method for fluoride determination in various kinds ofspices using microwave-supported sample preparation in high pressure oxygen atmosphere followed by potentiometry with a fluoride ion-selective electrode. Parameters of the microwave device for combustion procedure were checked and optimized in order to find settings ensuring complete sample combustion and/or absorption of the analyte in the absorption solution. For the ion-selective electrode measurement, the technique of standard straight line was chosen. Concentrations of fluorides in spices and spice blends under investigation ranged from $3.15 \mathrm{mg} \cdot \mathrm{kg}^{-1}$ to $26.08 \mathrm{mg} \cdot \mathrm{kg}^{-1}$. In order to check the accuracy of the method Certified Reference Material Fluoride in Vegetation NIST 2695 was used and a good agreement between certified and found values was found. The precision expressed as the relative standard deviation ranged from $0.6 \%$ to $5.0 \%$. The method is fast, accurate and reliable for this kind of analysis. In recent literature data on fluoride concentrations in spices and/or spice blends have not been found.
\end{abstract}

Ion-selective electrode, sample preparation, plant material

Fluorine is an important trace element for both human and animal organism. Because of its reactivity, fluorine is present in the Earth's crust only in compound forms, namely fluorite $\left(\mathrm{CaF}_{2}\right)$ and cryolite $\left(\mathrm{Na}_{3} \mathrm{AlF}_{6}\right)$. In a human body, fluorine is present at concentrations comparable to those of iron. The total amount of fluorine ranges from $3.5 \mathrm{~g}$ to $4.0 \mathrm{~g}$. As much as $99 \%$ of the total body fluorine is contained in bones and teeth in the form of hydroxyfluoroapatite. In teeth, fluorine is built into both dentine and enamel. From the bones, fluorine can be released into the body environment as necessary. Fluorine is usually easily absorbed from its salts in the gastrointestinal tract. Nevertheless, the presence of some ions, namely calcium, magnesium and aluminium could diminish its absorption substantially (up to one half). In the blood, fluorine is present predominately in its inorganic form. Fluorine is eliminated principally via urine. Small amount is also excreted by sweat, saliva and faeces. Additionally, small amount of fluorine is contained in milk. Acute intoxication caused by fluorine is rare. Depending upon the fluorine content of the environment, a long-term intake of higher fluorine amounts could be a reason for chronic intoxication with typical manifestations, fluorosis. There are two typical forms of fluorosis: dental and skeletal fluorisis. Also aluminiumfluoride complexes were found to be a very dangerous group of substances for both animal and human organisms. (Anke 2004; Report WHO 2006). From the soil, fluorine is transferred into the plant through its root system. The transferred amount depends predominantly on soil composition. Additionally, it could be also affected by local environmental conditions. The toxicity of fluorine for plants is relatively low. Intoxication could cause changes in plant appearance and/or growth. There are some plants in which fluorine is accumulated to a greater extent. The accumulation is not regularly dispersed throughout the whole plant organism but rather contained

Address for correspondence:

Emanuel Šucman

Institute of Biochemistry, Chemistry and Biophysics

University of Veterinary and Pharmaceutical Sciences Brno

Palackého tř. 1/3, 61242 Brno, Czech Republic 
in particular parts, e.g. leaves. Tea is an example of plant organisms which are well known to accumulate fluorine (Report WHO 2006). Spices used in food production could also contribute to fluorine intake. There is a lack of data on the fluorine content in these plant materials. Additionally, concentrations of fluoride in this kind of material are not regularly checked.

Since the introduction of the fluoride ion-selective electrode (F-ISE) into analytical chemistry, potentiometry with F-ISE became the method of choice in many applications, among them, food analysis (Semler et al. 1990; Malde et al. 2001). Alongside potentiometry, other methods have been used for determination of fluoride e.g. polarography (Guanghan et al. 1991; Lu et al. 1999), spectrophotometry (Tušl 1968; Khalifa and Hafez 1998), gas chromatography (Ćápka et al. 2004) or activation analysis (Chaudhri et al. 2007). The important part of the analytical system is the sample preparation step. Many procedures have been described (Krakovská and Kuss 2001) based upon dry ashing and/or wet digestion methods. The use of various microwave techniques in analytical chemistry is still growing especially in the field of sample preparation. Microwave-supported techniques have become sophisticated, reliable, fast and robust methods meeting the requirements of instrumental analytical techniques.

This study was focused on the determination of fluorine in spices. The aim of this study was to elaborate a method for fluoride determination in plant material (herbs and spices) using microwave-supported combustion in oxygen atmosphere, followed by the potentiometric measurement using a fluoride ion-selective electrode.

\section{Materials and Methods}

All reagents were of Suprapur Grade (Merck, Germany). Ultrapure water NANOpure (Branstead, USA) having specific conductance of less than $1 \mu \mathrm{S} / \mathrm{m}$ was used for sample and/or standard solutions preparation.

The microwave digestion system Multiwave 3000 (A. PAAR GmbH, Austria) was used equipped with thickwall quartz vessels XQ80 (100 ml).

\section{Samples}

Fifteen different kinds of herbs and spices (marjoram, black pepper, celery, dill, basil, garlic, onion, chili, sweet red pepper, hot red pepper, clove, cinnamon, parsley, bay leaf, mustard) and three spice blends (Ostrava sausage, wine sausage, Gothaj salami) were taken as samples for analysis. Samples were randomly bought through the trade network (producers: Vitana joint stock company, Bylinkárna Naturalis) and/or obtained from TRUMF International Ltd. In order to check the accuracy of results, Certified Reference Material (SRM Fluoride in Vegetation NIST 2695 - Low Level, USA) was used.

\section{Labware cleaning}

All labware was cleaned using $100 \mathrm{~g} / 1 \mathrm{HNO}_{3}$. Vessels, stoppers, flasks etc. were first soaked in $100 \mathrm{~g} / 1 \mathrm{HNO}$, for at least $12 \mathrm{~h}$, then rinsed with ultrapure water and soaked in ultrapure water for at least another $12 \mathrm{~h}$. Finally they were thoroughly rinsed with ultrapure water and stored/kept in closed dust-free housing till used. The combustion cuvettes were cleaned by a special microwave procedure described below.

\section{Microwave cleaning programme}

This programme was used to clean quartz cuvettes after each combustion procedure. The vessel was filled with $6 \mathrm{ml}$ of concentrated $\mathrm{HNO}_{3}$. The sample holder was inserted into the vessel and finally a Teflon stopper was used to close it. Four cuvettes were then placed into the Multiwave 3000 rotor. Rotor safety cover was closed and placed into microwave oven. The duration of the cleaning program was $1 \mathrm{~h}$ (see Table 1).

Table 1. Microwave oven cleaning program parameters

\begin{tabular}{lcccc}
\hline Step & Power $(\mathrm{W})$ & Ramp $(\mathrm{min})$ & Hold $(\mathrm{min})$ & Fan level \\
\hline Heating & 800 & 0 & 30 & 1 \\
Cooling & 0 & 0 & 30 & 3 \\
\hline
\end{tabular}


Table 2. Microwave oven combustion program parameters

\begin{tabular}{lcccc}
\hline Step & Power $(\mathrm{W})$ & Ramp $(\mathrm{min})$ & Hold (min) & Fan level \\
\hline Combustion & 1400 & 0 & 1 & 1 \\
Absorption & 400 & 0 & 5 & 15 \\
Cooling & 0 & 0 & 15 & 3 \\
\hline
\end{tabular}

Microwave digestion

The optimized microwave oven program parameters are given in the Table 2. Sample (about $150 \mathrm{mg}$ weight) was wrapped in a cellophane bag, placed on a quartz sample holder and inserted into a thick-walled quartz combustion vessel. In order to initiate the combustion a small disc of an ashless filter paper soaked with $100 \mu \mathrm{NH}_{4} \mathrm{NO}_{3}$ solution $\left(0.5 \mathrm{~g} \cdot \mathrm{ml}^{-1}\right)$ was used. The paper disc was placed under the sample bag. The vessel was then closed with special stopper equipped with a valve system which enables the vessel to be filled with oxygen. The oxygen filling procedure took approximately $10 \mathrm{~s}$ using $12 \mathrm{MPa}$ oxygen pressure. Products of combustion process were absorbed in $10 \mathrm{ml}$ of the absorption solution which consisted of $8 \mathrm{mmol} \cdot 1^{-1} \mathrm{Na}_{2} \mathrm{CO}_{3}$ a $1 \mathrm{mmol} \cdot \mathrm{l}^{-1}$ $\mathrm{NaHCO}_{3}$ mixture. After finishing the combustion procedure, the solution was quantitatively transferred from the quartz vessel into a $25 \mathrm{ml}$ volumetric flask and filled up to the mark with the TISAB solution. Thus prepared sample solution was used for potentiometric measurements.

\section{Potentiometry}

For potentiometric measurements the $940 \mathrm{pH} / \mathrm{ISE}$ Meter (Thermo ORION, USA) was used. The electrode system consisted of F-ISE type 9409 BN (Thermo ORION) and the reference argentchloride electrode, type RAE 111 (Monokrystaly, Czech Republic). The pH measurements were done using the 82-72BN, PerpHecT ${ }^{\circledR} \mathrm{ROSS}^{\mathrm{TM}}$ Sure-Flow ${ }^{\mathbb{B}}$ Electrode (Thermo ORION). The TISAB solution was used to adjust the $\mathrm{pH}(\mathrm{pH}=5.5)$ and to keep the constant ionic strength of measured solutions (both standards and samples). For the composition of TISAB see e.g. Semler et al. (1990).

Measurements were evaluated using the method of calibration straight line which was linear in the concentration interval from $6 \cdot 10^{-6} \mathrm{~mol} / 1$ to $8 \cdot 10^{-5} \mathrm{~mol} / 1$.

\section{Results}

The NIST SRM 2695 (Fluoride in Vegetation - Low Level) was used in order to check the accuracy of the described procedure. The mean value of $60.26 \mathrm{mg} \cdot \mathrm{kg}^{-1}$ and the $95 \%$ confidence interval $(60.26 \pm 6.90) \mathrm{mg} \cdot \mathrm{kg}^{-1}$ were found. The relative standard deviation was

Table 3. Fluoride content in herbs and spices

\begin{tabular}{lccccc}
\hline Kind & Country & $\mathrm{n}$ & Mean $(\mathrm{mg} / \mathrm{kg})$ & $95 \% \mathrm{CI}$ & $\mathrm{CV}(\%)$ \\
\hline Marjoram & Egypt & 6 & 10.59 & $10.48-10.71$ & 0.9 \\
Black pepper (minced) & Indonesia & 6 & 9.78 & $9.46-10.10$ & 3.1 \\
Celery & CR & 6 & 9.73 & $10.19-10.30$ & 5.3 \\
Dill & CR & 6 & 8.97 & $8.93-9.01$ & 0.4 \\
Basil & Egypt & 6 & 8.85 & $8.16-54$ & 7.5 \\
Garlic granules & Spain & 6 & 8.73 & $8.04-9.42$ & 7.4 \\
Onion slices & Greece & 6 & 8.63 & $7.87-9.39$ & 8.4 \\
Chili & China & 6 & 8.13 & $7.62-8.64$ & 5.9 \\
Red pepper (sweet) & Spain & 6 & 8.04 & $7.61-8.47$ & 5.0 \\
Red pepper (hot) & Spain & 6 & 7.82 & $7.08-8.56$ & 9.0 \\
Clove & Spain & 6 & 7.03 & $6.55-.51$ & 6.4 \\
Cinnamon & Mexico & 6 & 6.95 & $6.50-7.40$ & 6.2 \\
Parsley (leaves) & CR & 6 & 6.93 & $6.72-7.14$ & 2.9 \\
Bay leaf & Turkey & 6 & 6.33 & $6.24-6.42$ & 1.4 \\
Mustard (seeds) & CR & 6 & 3.95 & $3.93-3.97$ & 0.5 \\
\hline
\end{tabular}

$\mathrm{n}$ - number of determinations, $95 \% \mathrm{CI}-95 \%$ confidence interval, $\mathrm{CV}$ - coefficient of variation 
Table 4. Fluoride content in spice blends

\begin{tabular}{lllccc}
\hline Kind & Producer & $\mathrm{n}$ & Mean $(\mathrm{mg} / \mathrm{kg})$ & $95 \% \mathrm{CI}$ & $\mathrm{CV}(\%)$ \\
\hline Ostrava sausage & TRUMF Int. & 6 & 33.57 & $31.95-5.19$ & 4.6 \\
Wine sausage & TRUMF Int. & 6 & 5.26 & $5.20-5.32$ & 1.1 \\
Gothaj salami & TRUMF Int. & 6 & 3.15 & $3.08-3.22$ & 2.1 \\
\hline
\end{tabular}

$\mathrm{n}$ - number of determinations, $95 \% \mathrm{CI}-95 \%$ confidence interval, $\mathrm{CV}$ - coefficient of variation

$0.7 \%$. Because the certified value is $64 \pm 8.4 \mathrm{mg} \cdot \mathrm{kg}^{-1}$, it could be stated that the accuracy of the method is satisfactory.

In Tables 3 and 4 the results for fluorine content in various sorts of herbs, spices and spice blends are reported. The results are based upon six determinations. The relative standard deviation ranged from $0.6 \%$ to $5.0 \%$.

\section{Discussion}

The mean content of fluoride in various sorts of spices under investigation was found to range from $3.95 \mathrm{mg} \cdot \mathrm{kg}^{-1}$ (dried garlic) to $26.08 \mathrm{mg} \cdot \mathrm{kg}^{-1}$ (mustard seeds). The whole procedure is relatively fast. Determination of one sample (including the sample preparation step and two measurements with ISE) takes $30 \mathrm{~min}$. Both the accuracy and the precision of the method are satisfactory for this kind of analysis. It follows from the results that the contribution of herbs, spices and/or spice mixtures to the fluorine content of food is not critical. In terms of meat products, phosphates appear to be a much more serious source of fluorides (Synek et al. 1978). The main reason of this investigation was to develop and verify a new, fast and reliable method for determination of fluoride in various sorts of spices. The results given in Table 3 may not represent typical fluoride contents in various kinds of herbs and spices. For this reason, many more samples should be analysed and additionally classified with respect to different parameters, e.g. region of their origin. No comparable data are available.

\section{Acknowledgements}

This research was supported by the Ministry of Education, Youth and Physical Training of the Czech Republic (Research Plan Veterinary Aspects of Food Quality and Safety, MSM 6215712402).

\section{References}

Anke M, Ihnat M, Stoepler M 2004: Elements and their compounds in the environment. Vol. 3. Wiley-VCH, Weinheim: 1415-1421

Čápka V, Browers CP, Narvesen JN, Rossi RF 2004: determination of total fluorine in blood at trace concentration levels by the Wickbold decomposition method with direct potentiometric detection. Talanta 64: 869-878

Guanghan L, Qiongling W, Xiaogang W, Tong Z, Xin Y. 1999: Polarographic determination of trace fluoride in foods. Food Chem 66: 519-523

Guanghan L, Xiaoming L, Zhike H, Shuanglong H 1991: Polarographic determination of fluoride using the absorption wave of the Ce(III) alizarin complexon-fluoride complex. Talanta 38: 977-979

Khalifa ME, Hafez MAH1998: spectrophotometric and complexometric methods for the determination of thorium and fluoride using bromocresol orange reagent, Talanta 47: 547-559

Krakovská E, Kuss H-M 2001: Decompositions in analytical chemistry (in Slovak) Vienala, Košice pp. 226

Malde MK, Bjorvant K, Julshamn K 2001: Determination fluoride in food by the use of alkali fusion and fluoride ion-selective electrode. Food Chem 73: 373-379

Report WHO, Environmental health criteria, fluorine and fluorides. Available at: http://www.inchem.org/ documents/ehc/ehc/ehc36.htm. Last modified December 20, 2006, Accessed November 29, 2011

Semler M, Šucman E, Panoch M, Cvak Z, Dulová V 1990: Ion-selective electrodes and their use in food and agricultural praxis (in Czech) SVTI-PP, Praha, pp. 214 
Synek O, Šucman E, Šucmanová M 1978: Determination of fluorides in feeding phosphates. Acta Vet (Brno) 47: $159-162$

Tušl J 1968: Determination of fluorine in pure phosphorus compounds by La(III) alizarin complexon-fluoride complex after separation by microdistillation (in Czech) Chemické listy 62: 839-842 